\title{
Let the Buyer in the Ordinary Course of Business Beware: Suggestions for Revising the Prose of the Uniform Commercial Code ${ }^{1}$
}

\author{
George D. Gopen $\dagger$
}

\section{I. "If it Ain't Broke, Don't Fix It."}

Is the UCC "broke?" That seems to be a matter of perspective. Can it be "fixed?" That turns out to be a matter of rhetorical methodology. This article will argue that in important ways the Code is indeed "broke" and that currently available methods can repair the rhetorical damage without altering the substance of the Code's provisions.

If "broke" means "non-functional," then for the most part the UCC is not "broke." It is in use in all states but one and is referred to in legal decisions made every day. If, on the other hand, "broke" means "not functioning as well as it ought to," the Code's brokenness is evident and merits some attention.

Consider the following analogy. You have driven your car for many years and are quite attached to it, through sheer familiarity of use. Others tell you it's inefficient, underequipped, even downright unrespectable, but you reject their criticisms. After all, it's your car; they don't have to use it. Being intimately in touch with its quirks, its difficulties, and its lack of elegance, you have learned to adapt.

Then something unexpected happens: You buy a raffle ticket for a local charity, and, wonder of wonders, you win the grand prize-a new car, one on the cutting edge of automotive technology. It does all things that your old car can no longer do or could never do. You can accelerate or brake at the slightest and most

$\dagger$ George D. Gopen received his Ph.D. in English and his law degree both from Harvard. He is presently Director of Writing Programs at Duke University, where he is a member of the English Department. He has taught legal writing for several years as Lecturer on Law at the Harvard Law School.

'I have chosen the Uniform Commercial Code ("UCC") to explore only because its rhetorical difficulties are so specific, so consistent, and so well known to lawyers and law students. The principles suggested here can be used and expanded to apply to any statutes or agreements that are burdened with similar difficulties. 
sensitive touch of the foot; you can take corners in perfect parabolas; you can leave the local gas station with a heavier pocket and a lighter heart; and you can hear with utmost clarity your favorite music digitally reproduced from all four corners of your new automotive environment. After a few days, you wonder how you had ever functioned without all this control, this efficiency, and this elegance. Was your old car "broke?" You do not bother yourself with the metaphysics of the question; you're just grateful for the greater responsiveness of your present automobile.

For "transportation," read "communication;" for "car," read "Code." We may be so accustomed to the prose of the Code that we can perceive no real need to trade it in on a newer model (only recently made available). ${ }^{2}$ It is my argument that the newer model is worth the effort involved in the trade-in.

The prolix and convoluted style of the UCC works against many of the goals that its uniformity and broad acceptance were intended to achieve. That style condescends to the reader's needs for substantive clarity by pretending that professionals should have no such needs. It conflates multiple points until no intended demonstration of emphasis can be agreed upon by a community of readers. It forces readers to use so much intellectual energy to discover structure that on first reading (and on many rereadings) there is little energy left for discerning substance.

We need not be misled into inaction by the argument that most people who need to use the Code are practitioners, many of whom are specialists in the material. Nor need we be falsely comforted in that we now expect statutory rhetoric to require multiple readings of the utmost intensity. The UCC remains far more difficult to read, far more unwieldy to work with, than it need be or than it ought to be. Statutes may begin as publicly negotiated settlements of a particular legal problem; but immediately upon enactment they become instruction manuals for those who must use them in the future. Instruction manuals must be clear, to the point, and, above all, helpful.

A number of important considerations make it worth the effort to revise the Code's language:

2 The methodology presented in this article has evolved in the last decade from the combined work of the present author and three colleagues: Professors Joseph Williams and Frank Kinahan of the University of Chicaga, and Gregory Colomb of the Georgia Institute of Technology. Together we have acted as writing consultants for law firms, corporate legal departments, governmental agencies, and legal associations across the country. The principles, therefore, are not exclusively theoretical; they have already been put to use with success in the legal marketplace and have benefitted from the honing they have received there. 
1) The unwieldy style of the UCC reinforces the mystique of legal language being necessarily impenetrable; it therefore acts as a corrupt rhetorical model for students, practitioners, legislatures, and institutes to imitate. Currently acceptable statutory style and contractual boiler plate are often considered rhetorically inviolable by their caretakers across the country, partly out of fear that adjudicated substance will evaporate with syntactical change, and partly out of an inability to articulate complex thought clearly. I am not suggesting that we apply current "Plain English" techniques to the UCC, diluting the pea soup to make it palatable to the general public; I am suggesting that we can revise the organization of the prose without jettisoning any of the professional terms of art - to make it far more "user friendly."

2) The UCC's language creates unnecessary ambiguities in the substance of the law. Some of these are caused by overloaded sentence structures; ${ }^{3}$ others are caused by careless and inconsistent diction. ${ }^{4}$ Both of these problems can be treated without altering the substance of the provisions.

3) The Code's language wastes the time and mental energy of most who use it, which in turn probably multiplies the hours billed to clients for whom it is used. The significance of this waste should not be underestimated. In teaching principles of clear prose to lawyers across the country, I have heard a great many complaints at the program's end regarding how much they now resent the life blood they have to expend daily on reading other lawyers' impenetrable prose. Their anger increased the more they realized how little effort it takes, given the rhetorical principles suggested below, to make the crooked straight.

4) The Code's language makes a centrally important, uniform body of widely influential commercial law unavailable to nonlawyers. While the Code exists to state the law in such a way that practitioners may know how to function, the availability of its concepts to professional businesspersons should be considered an added advantage.

These problems, taken together, seem to me of great enough

${ }^{3}$ See the examples presented in Section IIIA of this article.

- For a good set of unfortunately unheeded criticisms, see David Mellinkoff, The Language of the Uniform Commercial Code, 77 Yale L.J. 185 (1967). 
significance to warrant an effort to rewrite the UCC, but only if all of the following are possible:

a) That the revision be done not in an ad hoc manner, section by section, but rather under a set of rhetorical principles that produces consistent structural and stylistic changes;

b) That these principles produce structures that are consistent with the structural expectations of educated readers of American English prose;

c) That the resulting changes in prose style and structure be perceived by a representative number of experts on the UCC as not having made changes in the substance of the law.

In the remaining pages of this article I wish to demonstrate some of the principles of revision that would achieve these objectives.

\section{II. "Simplify, Clarify, and Modernize"}

The UCC defines its own rhetorical purposes in $\S 1-102:^{5}$

(2) Underlying purposes and policies of this Act are

(a) to simplify, clarify and modernize the law governing commercial transactions. ...

To judge whether the Code succeeded entirely in its purposes, we need look no further than $\S 3-417$, which reads as follows:

(1) Any person who obtains payment or acceptance and any prior transferor warrants to a person who in good faith pays or accepts that

(a) he has a good title to the instrument or is authorized to obtain payment or acceptance on behalf of one who has a good title; and

(b) he has no knowledge that the signature of the maker or drawer is unauthorized, except that this warranty is not given by a holder in due course acting in good faith

(i) to a maker with respect to the maker's own sig-

s UCC § 1-102. All statutory references in both the text and the notes will be to the UCC, and in the remainder of the article references to the UCC will be by section number alone. 
nature; or

(ii) to a drawer with respect to the drawer's own signature, whether or not the drawer is also the drawee; or

(iii) to an acceptor of a draft if the holder in due course took the draft after the acceptance or obtained the acceptance without knowledge that the drawer's signature was unauthorized; and

(c) the instrument has not been materially altered, except that this warranty is not given by a holder in due course acting in good faith

(i) to the maker of a note; or

(ii) to the drawer of a draft whether or not the drawer is also the drawee; or

(iii) to the acceptor of a draft with respect to an alteration made prior to the acceptance if the holder in due course took the draft after the acceptance, even though the acceptance provided "payable as originally drawn" or equivalent terms; or

(iv) to the acceptor of a draft with respect to an alteration made after the acceptance.

"Simplify, clarify and modernize:" We might be able to grant this subsection its modernity, but hardly its simplicity and clarity. We might even be able to entertain an argument that $\S 3-417(1)$ is simpler and clearer than was the state of the law before the UCC: There may have been individual attempts by dozens of different legal communities to handle the problems involved, thus creating a chaos next to which $\S 3-417$ (1) appeared to be simplicity and clarity itself. I do not wish in any way to underestimate or undervalue the depth of study, the extent of effort, or the breadth of vision of those who drafted the Code. From Karl Llewellyn's astounding one-man effort through the revisions of the multitudinous committee members (who require six pages of acknowledgements in the current official text), the collective legal eye has indeed been on the simplification and clarification of the state of the law; it has not, however, taken enough heed of the need to simplify and clarify the articulation of the law. Now that we have a text, it is time to make it as simple, clear, and consistent as it possibly can be. 
I might begin with the problem of making definitions coherent and keeping them consistent, but that task has already been attended to by David Mellinkoff. ${ }^{6}$ The problem, however, is still with us. Mellinkoff wrote his article in 1967; twenty years later, I cannot find a single change in the UCC that remedies any of the definitional problems he raised.

Some of the problems pointed out by Mellinkoff are merely annoying extra burdens for the reader: for example, the Code stipulates that "unless the context otherwise requires, words in the singular number include the plural, and in the plural include the singular;" nevertheless, littered throughout the Code one can find the unnecessary duplications of "document and documents," "survivor and survivors," and the like. ${ }^{8}$

Other of Mellinkoff's complaints, however, seem so fundamentally troubling that they should have been responded to long before this. Here is a relatively simple one:

Some of the things the UCC calls 'definitions' have hardly any meaning-some no meaning at all-because they are circular. They define a word with the same word, or with a variation of the word so close that you return to the starting point almost unscathed by information. Sometimes the circuit is short and easy to trace; sometimes the circuit winds over hill and dale before sneaking back on itself.

One of the shorter circuits strewn through the UCC is rights-remedies. A definition tells you:

'Remedy' means any remedial right to which an aggrieved party is entitled with or without resort to a tribunal.

Two paragraphs on, another definition tells you:

'Rights' includes remedies.

Just like that; you are now back at remedy. And to make sense of both definitions you had best spell out remedial right, which, as anyone can see means a right, including the remedy, which means a remedial right, unless the context otherwise requires, in which case you can stay overnight. ${ }^{9}$

- See Mellinkoff, 77 Yale L.J. 185 (cited in note 4).

₹ 1 1-102(5).

See $\S 5-103(1)(b)$ and $\S 8-308(8)(d)$. See also Mellinkoff, 77 Yale L.J. at 190 (cited in note 4). Note especially that the latter subsection (formerly $\S 8-308(3)(e)$ ) has been rewritten since the Mellinkoff article-still without making the simplification he suggested.

- Mellinkoff, 77 Yale L.J. at 191 (cited in note 4). He quotes from $\$ 1-201(34)$ and $\$ 1$ 201(36) (emphasis added by Mellinkoff). 
He continues the point by mapping a far more complex (and therefore more perplexing) circuit between the terms "negotiation," "holder," and "indorsement," showing how a search for the meaning of any one of them leads the searcher back to the starting line, unencumbered by greater wisdom. ${ }^{10}$

Mellinkoff's work must be reread, reconsidered, and acted upon. Fortunately, today's technology allows us to identify these definitional problems without the need for the kind of supersleuthing that must have been necessary for him. Computer "search" capabilities render discovering the inconsistencies relatively easy; remedying them will take a greater effort, but not a Herculean one. By itself, however, streamlining definitions will not achieve the UCC goals of simplicity and clarity. If all the terms in $\S 3-417(1)$ were perfectly defined there or elsewhere in the Code, the subsection would still produce agony and confusion for its readers. What we need are principles of revision that take into account not only the law, but also the reader.

\section{Reader Expectations and the Revision of Prose}

The drafters of the UCC knew what they were writing about. They were steeped in the history of the provisions, the problems involved with the varieties of solutions in use in various states, and the difficulties of consolidating all of that into a single articulation of transactional law. Their process of collection and standardization, by the very nature of the task, had to be one of addition and subtraction. Out things came; in things went; and these things found homes wherever logic might dictate and the syntax would allow. The drafters, having been so immersed in their task, could hardly have been expected to perceive the resulting prose from the perspective of a reader who had not taken part in the drafting process.

Readers and users of the UCC must take the document as they find it. They have no sense of the complicated drafting process. Their experience is completely linear: what comes first on the page comes first in their perception. That which interrupts or qualifies on the page, interrupts and qualifies the process of reading, and hence the process of perceiving. Therefore, in order to revise the UCC, we need to know how readers contrive to perceive sentences and paragraphs during the reading process.

We now have a new methodology for the revision of prose,

${ }^{10}$ Mellinkoff, 77 Yale L.J. at 192 (cited in note 4). 
based not on what would be good strategies for a writer but rather on what needs and expectations exist for the reader. "Reader expectation theory" 11 was born of the linguistic discovery that readers expect certain components of the substance of prose (especially context, action, and emphatic material) to appear in certain welldefined places in the structure of prose. Once aware of these structural locations, a writer can consciously refashion and manipulate a piece of writing to maximize the likelihood that a reader will find in the prose precisely what the writer intended the reader to find.

Readers have a limited amount of what I call "reader energy" for the task of reading each different unit of discourse. A unit of discourse is anything in prose that has a beginning and an end: a phrase, clause, sentence, paragraph, section, subsection, book, etc. Since there are many different units of discourse functioning simultaneously, the reader energies needed for reading them function in a similarly complex simultaneity: one reads a clause while reading its sentence, which is also part of a subsection, and so on. Each of those energies is used for the performance of two major tasks: (1) for perceiving structure (how the discourse fits together as a unit); and (2) for perceiving substance (what the unit of discourse was intended to communicate).

For the most part, the distribution of this energy has a sumzero result; whatever energy is devoted to one of these tasks is thereby not available for the other. For most expository prose, one almost could define bad writing as that which demands a disproportionate amount of reader energy for the discovering of structure. If a reader is expending most of the available reader energy in trying to figure out the syntax of a sentence or the connections between successive sentences, that reader can have precious little energy left for considering the ideas that are in the process of being communicated. Conversely, if the signs of resolution and connection appear exactly where the reader expects them to appear, the reader can then devote most of the available "reader energy" to perceiving the nature of the substantive thought.

Armed with principles of reader expectation, a writer can make relatively objective judgments as to the likelihood of a reader

1 The term "reader expectation theory" is used here for the first time. The concept will be more fully developed in the author's book-length manuscript, now in progress. For many of its principles, see Joseph M. Williams, Style: Ten Lessons in Clarity \& Grace (2d ed. 1985); George D. Gopen, Perceiving Structure, Harv.L.School Bull., 27 (Summer/Fall 1984); George D. Gopen, The State of Legal Writing: Res Ipsa Loquitur, - Mich.L.Rev. - (forthcoming). 
perceiving from a piece of prose what the writer intended to communicate. The writer can be assured that when these structural principles are continually violated, the chances of reader misinterpretation greatly increase. Not only can the writer lower those threatening odds by repairing the structural damages, but the writer who is familiar with the relevant structural principles will know precisely where to focus the efforts at revision.

Instead of trying to list and explain all of these reader expectations by themselves, I will proceed by citing various problematic sections of the UCC, noting the structural difficulties in the writing, suggesting principles by which they could be revised, and then offering possible revisions. I will make every effort to avoid changing anything of the substance. This procedure could be followed for the entire UCC. If the revised versions suggested below are indeed significantly easier to read and to work with, and if this "translation" indeed avoids changing the substance of the prose, then it would be worthwhile to apply the principles to the entire UCC. ${ }^{12}$

A. The Stress Position; Parallel Structures; Whose Story; and the Function of Verbs

We can begin with an early sub-section, one that intends to function generally for the Code as a whole.

§ 1-102(3) . . . Variation by Agreement (original)

The effect of provisions of this Act may be varied by agreement, except as otherwise provided in this Act and except that the obligations of good faith, diligence, reasonableness and care prescribed by this Act may not be disclaimed by agreement but the parties may by agreement determine the standards by which the performance of such obligations is to be measured if such standards are not manifestly unreasonable.

This single sentence sub-section contains 68 words; but its mere length is not the cause of its difficulties. Despite claims to the contrary made by some creators of readability formulas, long sentences need not be difficult to read; they are only more difficult to write. I have seen sentences of well over a hundred words that flowed easily and persuasively toward their clearly demarcated des-

12 Should there ever arise an ambiguity on the face of the revision that was not present in the original, we could resort to the original to clarify the ambiguity. 
tinations. Those well-wrought lengthy sentences all had something in common: they had one and only one point to make. The main trouble with $\S 1-102(3)$ is that is has more than one point to make but only one place in it to indicate emphasis to the reader.

In oral communication, there are many ways to indicate intended stress: volume, speed, or tessitura of voice; variations and accentuations of tone; gesticulation of hands, eyes, and eyebrows; "body English;" and others. In written communication, aside from a few "flag" words, we have only structure. In the structure of a sentence, readers tend to expect that the material the writer intends to emphasize will appear at the end of the sentence. In this essay I will refer to that location as the "stress position."13

When the stress position is occupied by a word that logically might be emphasized, a reader senses the writer intended it to be emphasized. Conversely, when the stress position is occupied by something that cannot logically have been intended for emphasis, the reader must select - from all the other possibilities in the midst of the sentence - the one or ones which seem most likely to have been the writer's choice. The longer the sentence, the more possibilities there are to plague the reader, resulting in a substantial variety of possible interpretations. $\S 1-102(3)$ includes many intended emphases. To clarify which they are, we need to create a stress position for each.

The stress position changes in size from sentence to sentence. Sometimes it is a single word; sometimes it can be several lines long. The definitive factor: a reader is in the stress position when the reader knows there is nothing but the present material left in the sentence. A whole list, numbered and indented, can be the stress position of a sentence if it has been clearly announced that the list is all that remains in that sentence. Each member of that list, in turn, may have its own internal stress position since stress positions are created by syntactic closure (a semi-colon, a colon, a period, or the end of a numbered and indented example). That concluding punctuation mark tells a reader to release the "reader energy" that has been used for the perception of the local ongoing syntax.

To improve $\S 1-102(3)$, therefore, we first need to decide which moments require emphasis and then to create stress positions for them. In doing this we might search for parallel points that appear only linearly in the original. By structuring them in parallel fash-

${ }^{13}$ The terms "stress position" and "topic position," see Section III.C. below, were chosen by my colleague Joseph Williams. See note 11. 
ion (by using parallel syntax and perhaps list form), they will appear parallel to the reader on first perception.

Unfortunately, $\S 1-102(3)$ is too complex to revise on this principle alone. A second and a third principle are necessary in order to do this job well.

Our second reader expectation: Readers expect a unit of discourse to be about whoever shows up first. "John loves Mary" and "Mary is loved by John" are two different sentences about the same facts. The first tells us something about John, the second about Mary. Despite the passivity of the second, both are good sentences. "John loves Mary" is actually an inferior sentence to "Mary is loved by John" if the former sentence appears in a paragraph that is telling us all about Mary: We need, therefore, to put at the beginning of each unit of discourse the people (or things) whose "story" that unit intends to recount.

Yet a third reader expectation: Readers expect the action of a sentence to be located in the verb or in verb phrases. When that is the case, the reader can "hear" that the verb phrase is indeed the clause's action. When the verb phrase does not articulate the action, once again the reader must search for it elsewhere in the sentence, with no structural clue as to which of the several other words it might be. We need, therefore, to make sure that the actions that are taking place in $\S 1-102(3)$ occupy the verb slot. ${ }^{14}$

Putting together the principles of (1) placing emphatic material in stress positions, (2) announcing "whose story" it is at the beginning of discourse units, and (3) articulating action in the verb phrases, we can transform $\S 1-102(3)$ as follows:

$\S$ 1-102(3) . . . Variation by Agreement (revision)

Parties are free to agree to vary the effects of the provisions of this Act except

(a) when this Act explicitly provides otherwise, and

(b) when this Act prescribes obligations of good faith, diligence, reasonableness and care.

When the obligations listed in Section 1-102(3)(b) are in-

14 The existence of reader expectations does not necessitate the creation of rigid rules of composition. Any of these expectations can be violated to good effect. In fact, the greatest stylists are usually those who know best when and how these expectations should be violated. In general, however, the greater the need for clarity, the greater is the need that the reader's expectations be fulfilled. In a document like the UCC, attaining clarity should be the highest priority. 
volved, parties may agree to determine the standards by which the performance of the obligations is to be measured, as long as those standards are not manifestly unreasonable.

I reprint this revision below with the stress positions in curly brackets, the story focuses underlined, and the verb phrases in capital letters.

Parties ARE FREE TO AGREE TO VARY the effects of provisions of this Act except

(a) when this Act EXPLICITLY PROVIDES \{ otherwise $\}$, and

(b) when this Act PRESCRIBES obligations of \{ good faith, diligence, reasonableness, and care $\}$.

When the obligations listed in Section 1-102(3)(b) ARE INVOLVED, parties MAY AGREE TO DETERMINE the standards by which the performance of the obligations IS TO BE MEASURED, as long as those standards ARE \{ not manifestly unreasonable\}.

The new parallel structure has produced a section that has "the parties" as the primary agent, making it their story. They have the power to vary the effects of the Act except as delineated in the numbered exceptions, where "the Act" becomes the agent and prohibits them from doing so. The only other prohibition comes from the general concept of "reasonableness," which is given the final stress position. Note that the syntax of the revision offers three stress positions, compared to only one in the original; this creates three separate structures in which the three separate ideas of the original can be considered. ${ }^{15}$

1s All this still does not remove the problem of ambiguity concerning the word "care" that Mellinkoff describes at length:

What obligations of care are these words talking about? ... Are we talking here about obligations of care as a legal conclusion, whether or not the precise word care is used? $\mathrm{Or}$ is it only care described as care that is an obligation of care "prescribed by this Act"? Further, does the obligation of care mean both senses of care that the UCC deals with? There is care in the sense of being careful, variously described as care, ordinary care, reasonable care and the care of a reasonably careful man "under like circum. stances." There is also care in the sense of taking care of something, e.g., goods-"caring for and selling," "care and custody."

Mellinkoff, 77 Yale L.J. at 217-18 (footnotes omitted) (cited in note 4). My revision suggests a way to clear up the syntactical problem; Mellinkoff urges us to clear up the definitional problem. The two complement each other. 


\section{B. Subject-Verb-Complement Separation}

Another reader expectation: Readers generally expect a grammatical subject to be followed immediately by the verb, which will in turn be followed immediately by the complement of the sentence. Anything of length that intervenes between subject and verb or between verb and complement is read as an interruption, as something of lesser importance. The reader feels an actual need for the fulfillment that accompanies the arrival of the verb. As a result, the reader's attention is focused on that arrival and tends to resist being diverted to a recognition of the importance of the interrupting material.

I find subject-verb and verb-object interruptions some of the most common structural problems in legal prose. Lawyers seem to feel a great need to qualify every statement and half-statement before finishing the main point. It is almost as if they fear that some hostile force (judge, senior partner, adversary) might "jump in," preventing the qualification from being made, and thereby defeating the general point under consideration.

The UCC is filled with subject-verb interruptions. The longer an interruption continues, the more baggage the reader has to carry about while searching for the verb. If the interrupting material extends far enough, the reader eventually uses all of his or her available reader energy for perceiving structure; this in turn dissipates the energy that could have been used for perceiving substance and thereby necessitates a re-reading of the sentence. An example of this malformed structure is $\S 1-201(9)$.

\section{§ 1-201(9) from General Definitions (original)}

"Buyer in ordinary course of business" means a person who in good faith and without knowledge that the sale to him is in violation of the ownership rights or security interest of a third party in the goods buys in ordinary course from a person in the business of selling goods of that kind but does not include a pawnbroker. ... .

The "who" of the second clause must wait 28 words for its verb ("buys"). All the intervening material has been given reduced attention while the reader is busy searching for the verb. That material, it turns out, was precisely the material of importance that the drafters wished to emphasize. Notice that two violations of reader expectation are functioning here simultaneously: (1) The important material is undercut in emphasis by being located in the midst of a subject-verb separation; and (2) the important material 
is undercut in emphasis by being located elsewhere than in the stress position. Solutions? (1) Get the subject and verb together; and (2) create sufficient stress positions for all of the material that needs to be emphasized. The result:

\section{\$ 1-201(9) from General Definitions (revision)}

"Buyer in ordinary course of business" means a person who buys in ordinary course from a person in the business of selling goods of that kind, as long as the buyer acts

(a) in good faith, and

(b) without knowledge that the sale to him violates the ownership rights or security interest in the goods held by a third party.

This term does not apply to pawnbrokers.

Note the many interesting results of this revision. The original burdened the reader throughout a tortuous syntactic journey, offering rest only at the end, the closure emphasizing the marginally important "pawnbrokers." (The effect was almost humorous.) Now the pawnbrokers have a little structure all to themselves, its very brevity indicating their lesser importance. "Good faith" and the rights of the "third party" have their own chance to shine. We have now a helpful checklist, easy to use.

But along with these improvements, a tautological silliness has surfaced. We realize that we have been told that a "[b]uyer in ordinary course of business" means "a person who buys in ordinary course from a person in the business. ..." This is far from helpful. Looking hard at the original, we discover that the same unhelpful information had been present there but was disguised by the convoluted syntax. Our structural revision has unearthed one of Mellinkoff's definitional problems. That problem will demand the kind of definitional improvements he has so ably suggested.

\section{Topic Position}

$\S 2-202$ combines some of the problems we have seen above but requires that even more care be exerted concerning whose story it really is.

$\S$ 2-202 Final Written Expression: Parol or Extrinsic Evidence (original)

Terms with respect to which the confirmatory memoranda of the parties agree or which are otherwise set forth in a writing 
intended by the parties as a final expression of their agreement with respect to such terms as are included therein may not be contradicted by evidence of any prior agreement or of a contemporaneous oral agreement but may be explained or supplemented

(a) by course of dealing or usage of trade (Section 1205 ) or by course of performance (Section 2-208); and

(b) by evidence of consistent additional terms unless the court finds the writing to have been intended also as a complete and exclusive statement of the terms of the agreement.

There are so many reader expectations violated by this section that we might have difficulty choosing where to start. Eventually we discover that with structural problems like these, it does not matter where we start, as long as we get around to all of them eventually. Each one affects each other.

I tend to start with what for me is the most apparent-yet another of those monstrous subject-verb separations. From "Terms" to "may not be contradicted" this one measures 40 words. When we get subject and verb together, we discover that the section seems to have a focus completely different from that which first appeared. It tells the story of "evidence of prior agreement," not of "terms with respect to which. ..."

I spoke above of the importance of how the beginning of a unit of discourse suggests "whose story" the discourse will be. Now let me christen this structural location the "topic position." Since any given topic position announces whose story this particular unit is, a number of consecutive topic positions being filled by the same occupant suggests to the reader that the story of that occupant is being told continuously. Conversely, when a topic position presents an occupant different from the previous one, the reader should be able to infer safely that the story's focus has shifted away from the previous occupant to the present occupant. Prose that fills the topic position in this manner with great consistency builds the reader's confidence and eliminates many an unnecessary ambiguity.

We began revising $\S 2-202$ by repairing the subject-verb rift. We then discovered that the wrong phrase occupied the topic positions. In further rearranging the prose to make sure 
that the stress positions were filled with the proper occupants, we discover that there were two stories being told here. The first is of parol evidence; it now occupies the primary topic position. The second turns out to be a sub-story about "terms;" they can therefore occupy topic positions in the subunits. Beyond that, there is a story of an exception concerning those terms. The need for stress positions for that story requires us to build a completely separate unit of discourse, in which "terms" is justly deserving of the topic position. The result:

$\S$ 2-202 Final Written Expression: Parol or Extrinsic Evidence (Revision)

(1) No evidence of any prior agreement or contemporaneous oral agreement may be used to contradict

(a) terms which the parties have agreed to in their confirmatory memoranda; or

(b) terms in a writing which the parties have intended as a final expression of their agreement.

(2) However, the terms referred to in (1)(a) and (1)(b) may be explained or supplemented

(a) by course of dealing or usage of trade (Section 1205);

(b) by course of performance (Section 2-208); or

(c) by evidence of consistent additional terms, unless

(i) the court finds the writing to have been intended also as a complete and exclusive statement of the terms of the agreement.

Note in the second subsection how simple it was to arrange the three indented methods neatly in parallel fashion, each with its own topic and stress positions. In this revision, the mind does not have to deal with a sub-unit of discourse longer than 15 words until the final sub-sub-exception, (2)(c)(i). We can afford to expend the extra energy at that point because we can see that the whole section is quickly coming to an end.

Investigating the structural question of what belongs in topic positions can lead to diverse kinds of discoveries, as a look at $\S 3$ - 
202 will demonstrate.

\section{§ 3-202 Negotiation (original)}

(1) Negotiation is the transfer of an instrument in such form that the transferee becomes a holder. If the instrument is payable to order it is negotiated by delivery with any necessary indorsement; if payable to bearer it is negotiated by delivery.

(2) An indorsement must be written by or on behalf of the holder and on the instrument or on a paper so firmly affixed thereto as to become a part thereof.

(3) An indorsement is effective for negotiation only when it conveys the entire instrument or any unpaid residue. If it purports to be of less it operates only as a partial assignment.

(4) Words of assignment, condition, waiver, guaranty, limitation or disclaimer of liability and the like accompanying an indorsement do not affect its character as an indorsement.

The section is entitled "Negotiation." The initial topic position is occupied by "Negotiation." The reader is convinced that this is a story about "Negotiation." But given that perspective, the reader discovers that most of the section is not to the point; it spends a great majority of its time attending to "indorsement"its requirements, its effects, and its invulnerabilities. The more one studies the section, the more it appears that even though the first main point has to do with "Negotiation," the torch is soon passed to "indorsement."

Given this progression, a simple process for revising the structure suggests itself: (1) Give "Negotiation" the first topic position; (2) eventually get "indorsement" into a significant stress position to indicate its importance; then (3) string "indorsement" from topic position to topic position until its story is completely told. The result:

\section{§ 3-202 Negotiation; Indorsement (revision)}

(1) Negotiation is the transfer of an instrument in such form that the transferee becomes a holder. If the instrument is payable to bearer it is negotiated by delivery; if payable to order it is negotiated by delivery with any necessary indorsement.

(a) An indorsement must be written by or on behalf of the holder and on the instrument or on a paper so firmly affixd thereto as to become a part thereof. 
(b) An indorsement is effective for negotiation only when it conveys the entire instrument or any unpaid residue. If it purports to be of less it operates only as a partial assignment.

(c) An indorsement remains an indorsement even if accompanied by words of assignment, condition, waiver, guaranty, limitation or disclaimer of liability and the like.

Compare where the word "indorsement" appears in this revision with where it appears in the original. In the current text of the UCC, "delivery," not "indorsement," gets the main stress position at first; then "indorsement" takes over for (2) and (3), but hides again in (4). In the revision, the bringing of "indorsement" to the topic position creates a natural parallel structure, which in turn makes it easier for the reader to catalogue its several characteristics.

The revision also made it apparent that "indorsement" is of such importance to $\S 3-202$ that it deserves mention in the title of the section. "Negotiation; Indorsement" prepares the reader properly for that which follows.

Since we eventually perceive that defining "indorsement" seems to be part of this section's purpose, we might well check for the term's presence in the definitional section of the whole Code ( $\$$ 1-201) or that of Article 3 (\$ 3-102). We do not find it. This discovery suggests that one of the following should happen:

1) Either a definition should be created in $\S 1-201$ (or $\S 3-102$ ) that is consistent with $\S 3-202$; or

2) If such a definition would take too much space for those sections, and if § 3-202 adequately defines "indorsement," then the term should be listed in § 1-201 and § 3-102 with the brief reference "See § 3-202."

It may then become apparent (through occasional cross-reference or even through a concordance check of "indorsement") that the term is not consistently applied throughout the UCC. This indeed seems to be the case. ${ }^{16}$ The structural revision of this one section could lead to resolving a Code-wide difficulty.

16 James J. White, Some Petty Complaints about Article Three, 65 Mich.L.Rev. 1315, 1326-29 (1967). 
D. Breathing; And/Or; Flags; Negatives; Exceptions

With several principles of revision now in place, it is possible to return to $\S 3-417$ (1) of the Code, the 246-word mammoth put on display at the beginning of Part II above. With only a few additional stylistic considerations, we can make even $\S 3-417(1)$ succumb to helpful revision.

§ 3-417 Warranties on Presentment and Transfer (original)

(1) Any person who obtains payment or acceptance and any prior transferor warrants to a person who in good faith pays or accepts that

(a) he has a good title to the instrument or is authorized to obtain payment or acceptance on behalf of one who has a good title; and

(b) he has no knowledge that the signature of the maker or drawer is unauthorized, except that this warranty is not given by a holder in due course acting in good faith

(i) to a maker with respect to the maker's own signature; or

(ii) to a drawer with respect to the drawer's own signature, whether or not the drawer is also the drawee; or

(iii) to an acceptor of a draft if the holder in due course took the draft after the acceptance or obtained the acceptance without knowledge that the drawer's signature was unauthorized; and

(c) the instrument has not been materially altered, except that this warranty is not given by a holder in due course acting in good faith

(i) to the maker of the note; or

(ii) to the drawer of a draft whether or not the drawer is also the drawee; or

(iii) to the acceptor of a draft with respect to an alteration made prior to the acceptance if the holder in due course took the draft after the acceptance, even though the acceptance provided "payable as originally drawn" or equivalent terms; or 
(iv) to the acceptor of a draft, with respect to an alteration made after the acceptance.

In addition to the problems enumerated so far, $\S 3-417(1)$ demonstrates four additional stylistic problems that recur throughout the UCC and which can be remedied relatively simply.

(1) It is often difficult to perceive whether the words "and" and "or" are being used (a) for joining phrases/clauses or (b) for joining parallel individual words within phrases/clauses. As a result, the reader often does not know whether to take a "mental breath" at a conjunction (in expectation of a whole new clause being about to start) or to continue the present mental breath (in order to join the next word to the word that preceded the conjunction). My suggestion: We should use "and" and "or" only to join phrases/clauses, using in their place a slash (/) to join individual words whenever necessary. The new compound slash-word will be read as the single unit it represents. ${ }^{17}$

(2) Semantic "flags" are often missing-especially words like "either," which signal the reader that a new series of alternatives has begun. Such words are the only indications of the organization of written prose other than structural positions like the ones discussed above. They should be used whenever they can help to diminish the possibility of ambiguity.

(3) Double negatives (and triple and quadruple negatives) most often leave the reader dizzy from mental revolutions. They should be avoided wherever possible.

(4) Exceptions to a general rule are too frequently included in the very sentence/subsection that articulates that general rule, making it seem that the generality includes both a positive

17 This will not create the kinds of problems we associate with noun strings. A reader has difficulty with noun strings because of the difficulty of perceiving whether the noun being read functions as a noun or an adjective. For example, "The systems analysis conference workbook answers key is available. ..." One knows "key" is the noun only because one realizes that "is" cannot be an addition to the string. By then it is too late. My suggested new compound slash-words can be seen quite clearly and therefore digested as a unit. I realize it might look strange to the eye at first, but this strange appearance is justified by the way in which lawyers tend to read such legal lists. I have found that once such a list is established in a text, a lawyer reading aloud will articulate clearly only the first member of the list, lowering the voice and speeding through the others. In effect, the lawyer is reading the list as a unit. If so, it would be reasonable to print it as a unit. 
and a negative, when in fact the generality is only one or the other. To make things worse, the exceptions usually require more space than the general rule, giving the reader a false impression of their relative importance: normally a reader expects that when presented with a short and a long, the long is intended to receive the greater emphasis because it requires more prolonged attention. My suggestion: Separate the exceptions from the general rule entirely, letting the reader know that the exceptions will follow below. That will allow the reader to comprehend the general rule without having simultaneously to wade through the complicated exceptions. It should be relatively easy to signal the reader that the exceptions exist; we need not worry that the rule might be perceived as existing without its exceptions.

Applying the structural principles and these four additional revision tactics, the revised version of $\S 3-417(1)$-almost precisely the same length as the original-demands significantly less effort from the reader.

\section{\$ 3-417 Warranties on Presentment and Transfer (revision)}

(1) Any person who either (i) is a prior transferor or (ii) obtains payment/acceptance, warrants the following to a person who in good faith pays/accepts:

(a) Either he personally has a good title to the instrument or is authorized to obtain payment/acceptance on behalf of one who has a good title; and

(b) He has no knowledge that the signature of the maker/drawer is unauthorized (See exception $\mathrm{E}(1)(\mathrm{b})$ below); and

(c) The instrument has not been materially altered (See exception $\mathrm{E}(1)(\mathrm{c})$ below).

EXCEPTIONS:

$\mathrm{E}(1)(\mathrm{b})$ This warranty is not given by a holder in due course acting in good faith to the following:

(i) a maker, with respect to the maker's own signature; or

(ii) a drawer, with respect to the drawer's own signature, whether or not the drawer is also the drawee; or

(iii) an acceptor of a draft, if the holder in due course either took the draft after the acceptance or obtained the ac- 
ceptance without knowledge that the drawer's signature was unauthorized.

$\mathrm{E}(1)$ (c) This warranty is not given by a holder in due course acting in good faith to the following:

(i) the maker of a note; or

(ii) the drawer of a draft, whether or not the drawer is also the drawee; or

(iii) the acceptor of a draft, with respect to an alteration made after the acceptance; or

(iv) the acceptor of a draft, with respect to an alteration made prior to the acceptance,

a) if the holder in due course took the draft after the acceptance, and

b) even though the acceptance provided 'payable as originally drawn' or other equivalent terms.

Certain of the changes made here are worth considering in some detail. For greater ease in making comparisons, I reprint portions of the section here in columns, the original on the left, the revision on the right.

(1) Any person who obtains payment or acceptance and any prior transferor warrants to a person who in good faith pays or accepts that
(1) Any person who either (i) is a prior transferor or (ii) obtains payment/acceptance, warrant the following to a person who in good faith pays/ accepts:

Comments: In the original, the "or" and the "and" are quite confusing on first reading, and even on many rereadings. At first the "or" might raise the expectation of another verb to balance "obtains." The "and" is equally ambiguous, suggesting that a possible compound object for "obtains" will follow. After that the "warrants" may add to the confusion, since it could conceivably function as a noun. Perhaps most difficult of all: once the ambiguities are resolved, the reader finds no point of closure here, and the strain of reading subsection (1) is carried over into the task of reading subsection (1)(a). Indeed, that burden is not relinquished until the end of subsection (1)(c)(iv).

The revisions accomplish the following: 
1) The additions of "either" and the numbers in parentheses make it clearer that "obtains" will be the first of two verbs (the second being "is"). The "or" announces to us the falling of the second shoe.

2) The slash replacing the "or" of the original avoids the ambiguities caused by the original conjunctions.

3) The "either . . . or" structure more clearly demarcates the end of the "who" clause and signals that "warrants" is indeed the long-awaited verb that attaches to the subject "person." ("Warrants" cannot be a noun because it would be improperly plural following "is." The ear hears this even quicker than the eye sees it.)

4) The reversing of the order of "prior transferor" and "obtains payment/acceptance" moves the latter closer to the person who "in good faith pays/accepts."

5) The addition of "the following" and the colon creates a stress position and allows the reader closure, the opportunity to take a mental breath before the long string of subsections and subsubsections.

(a) he has a good title to the instrument or is authorized to obtain payment or acceptance on behalf of one who has a good title; and (a) either he personally has a good title to the instrument or is authorized to obtain payment/aceptance on behalf of one who has a good title; and

Comments: The two uses of "or" in the original are confusing at first. The "either" of the revision flags the reader to expect a dichotomy, and the elimination of the second "or" takes away any possible ambiguity. The addition of "personally" warns the reader of the approaching alternate possibility for which personal possession of good title is unnecessary.

(b) he has no knowledge that the signature of the maker or drawer is unauthorized, except that this warranty is not given by a holder in due course acting in good faith (b) He has no knowledge that the signature of the maker/ drawer is unauthorized (See exception $\mathrm{E}(1)(\mathrm{b})$ below); and 
i) to a maker with respect to the maker's own signature; or

ii) to a drawer with respect to the drawer's own signature, whether or not the drawer is also the drawee; or

iii) to an acceptor of a draft if the holder in due course took the draft after the acceptance or obtained the acceptance without knowledge that the drawer's signature was unauthorized; and

Comments: One of the main reasons the original subsection (1)(b) might strike a reader as burdensome to read is its lack of proportion when compared to subsection (1)(a). In such a list, a reader tends to expect the (b) to be about the same length and importance as the (a) had been-unless there appear to be logical causes for an imbalance. If (b) is significantly longer and more complex than (a), it suggests that (b) is also significantly more important than (a); in that case we might wonder why the (b) had not been granted the (a) position on the list itself. In the original here, we start wandering through labyrinths while we want to be speeding down the straightaway. All of subsection (1)(b) is tacked on to an "and" at the end of subsection (1)(a), and our mental breath is suffering an asthmatic attack. The cruelest word of all in $\S 3$ $417(1)(a-c)$ is the "and" at the end of subsection (1)(b)(iii). To have to hold on to all of that and still add something more to it-oh dear.

The revision simply amputates the complicated and lengthy exceptions and leaves us with the general rule, easy to read and easy to digest: He warrants that he has no knowledge that the signature is unauthorized. ${ }^{18}$ Since that thought is parallel to the thought in (1)(a), it ought to appear in parallel form, unencumbered by the baggage; that will allow the reader to digest the essentials before having to deal with the details. Since the added pa-

18 I am keenly aware of the need to deal with the issue of sexist pronouns in this type of legislation. I leave the generalized "he" here with some reluctance and would recommend certain methods of evading sexist language, should a revision of the UCC eventually be undertaken. Actually, the addition of the "generic she" might be a welcome one for the UCC, creating the possibility for referring to two easily recognized persons in the same sentence. 
renthesis directs the reader to seek out the appropriate passage under "Exceptions" below, there should be no fear that the general rule will be read as the controlling rule in all cases.

Note also that separating the exceptions from the general rule does away with the problem of a triple or quadruple negative ("he has no knowledge. . .unauthorized. . .except. . is not given"). Problems with multiple negations often will be resolved by such separations, since the exception is normally a negative of the general rule.

The same observations hold true for $(1)(c)$ :

(c) the instrument has not been materially altered, except that this warranty is not given by a holder in due course acting in good faith

i) the maker . . . [3 words];

or

ii) the drawer . . . [12 words];

or

iii) the acceptor . . . [37 words];

or

iv) the acceptor . . .[12 words].

A general note on the suggested separation of the exceptions: They should be clearly marked and easily found. Perhaps they could be numbered to code them with their original subsections, prefacing the number with an "E" to indicate that they must be read as exceptions, not as rules by themselves. Grammatical adjustments should be made so that each exception will stand by itself as a sentence. This will help to create more full stress positions thereby solving the mental breath problem. The reader will have dealt with the general rule beforehand and can therefore devote fresh energy to considering the exceptions.

Most of the changes in the revised exceptions follow generally the kinds of changes made so far in this article. Here are the three which do not:

1) Notice how clearly the reader now can see that the exceptions in subsection (1)(c) are exactly parallel to those in subsection (1)(b). It had not been so easy to perceive that similarity in the original, where too many turns in the labyrinth destroyed 
the sense of parallelism.

2) Notice that the original of sub-subsection (c)(ii) omitted the comma before "whether," even though that comma had appeared in the parallel statement of the original sub-subsection (b)(ii). My point here is not so much that the drafters of this article have made a grammatical error, but rather that even they had lost sight somewhat of the parallel nature of subsubsections (b)(ii) and (c)(ii).

3) Notice that in the revision of subsection (c) I have switched the order of original sub-subsections (iii) and (iv). I imagine the drafters chose the original order because "before the acceptance" seems stylistically (though not, I would argue, logically) to belong before "after the transaction." That nicety for orderliness is outweighed, I think, by the general principle that when burdened with a long and a short, we should always try to position the short before the long. Readers find little difficulty in holding onto the memory of a short passage while working their way through a long one; the opposite causes problems. It is easier to put a newspaper under your arm before you pick up your typewriter than to try to do it the other way around.

Having proceeded at such a painfully slow pace through $\S 3$ 417(1), let us now take a brisk look at another large section (two sentences, 177 words) to which the same principles have been applied.

\section{§ 3-603 Payment or Satisfaction (original)}

(1) The liability of any party is discharged to the extent of his payment or satisfaction to the holder even though it is made with knowledge of a claim of another person to the instrument unless prior to such payment or satisfaction the person making the claim either supplies indemnity deemed adequate by the party seeking the discharge or enjoins payment or satisfaction by order of a court of competent jurisdiction in an action in which the adverse claimant and the holder are parties. This subsection does not, however, result in the discharge of the liability

(a) of a party who in bad faith pays or satisfies a holder who acquired the instrument by theft or who (unless having the rights of a holder in due course) holds through one who so acquired it; or 
(b) of a party (other than an intermediary bank or a payor bank which is not a depositary bank) who pays or satisfies the holder of an instrument which has been restrictively indorsed in a manner not consistent with the terms of such restrictive indorsement.

My revision:

§ 3-603 Payment or Satisfaction (revision)

(1) Any party is discharged of a liability to the extent that he pays/satisfies the holder, even though he does it with knowledge of an adverse claim to the instrument by another person. However, this subsection (1) does not result in discharge of liability for the following parties:

(a) a party who, prior to making payment/satisfaction, has received from an adverse claimant indemnity that the party considers adequate;

(b) a party whose attempt to pay/satisfy has been enjoined by order of a court of competent jurisdiction in an action brought by an adverse claimant to which both the adverse claimant and the holder are parties;

(c) a party who in bad faith pays/satisfies a holder who either

(i) acquired the instrument by theft, or

(ii) does not have the rights of a holder in due course and holds through one who acquired it by theft;

(d) a party who pays/satisfies the holder of a restrictively indorsed instrument in a manner not consistent with the terms of such restrictive indorsement.

(Exception: This subsection (d) does not apply to an intermediary bank or to a payor bank which is not a depositary bank.)

The main changes here: The topic positions of the section are now occupied in such a way that the story remains consistent throughout. It is now quite clearly the story of how parties are discharged or not discharged by paying or satisfying the holder. The actions have been transformed from nouns to verbs. The materials to be emphasized have been placed in the stress positions. The general rule has been separated from all the exceptions. 
The exceptions are arranged in parallel fashion so that one may easily see who is excepted and for what reasons. The "yes" is now distinct from the "no."

\section{Putting it All Together}

Having said a good deal about "reader expectation," it seems appropriate to do an actual "reading" of a particularly challenging section. Reducing the reading pace to ultra-slow-motion, even just for the first paragraph, should demonstrate adequately the extremity of the section's difficulties. The up-tempo of the revision that follows might then succeed in persuading us that the effort it would take to revise the entire UCC would be worthwhile.

\$ 4-303 When Items Subject to Notice, Stop-order, Legal Process, or Set-off; Order in Which Items May be Charged or Certified (original)

(1) Any knowledge, notice or stop-order received by, legal process served upon or setoff exercised by a payor bank, whether or not effective under other rules of law to terminate, suspend or modify the bank's right or duty to pay an item or to charge its customer's account for the item, comes too late to so terminate, suspend or modify such right or duty if the knowledge, notice, stop-order or legal process is received or served and a reasonable time for the bank to act thereon expires or the setoff is exercised after the bank has done any of the following:

(a) accepted or certified the item;

(b) paid the item in cash;

(c) settled for the item without reserving a right to revoke the settlement and without having such right under statute, clearing house rule or agreement;

(d) completed the process of posting the item to the indicated account of the drawer, maker or other person to be charged therewith or otherwise has evidenced by examination of such indicated account and by action its decision to pay the item; or

(e) become accountable for the amount of the item under subsection (1)(d) of Section 4-213 and Section 4-302 dealing with the payor bank's responsibility for late return of items. 
(2) Subject to the provisions of subsection (1) items may be accepted, paid, certified or charged to the indicated account of its customer in any order convenient to the bank.

Any 234-word sentence is likely to be rough going for a reader, even when read at statutory pace. But this particular construction burdens the reader with so many packages on the way to comprehension that even a professionally seasoned reader has to set them all down at some point and start over. It is not simply that the sentence is long; it is the way in which it is long.

The concept of the overburdened traveller becomes clearer if we take ourselves through a slow-motion replay of this reading experience:

"Any knowledge, notice or stop-order received by,. .."

Putting aside the minor annoyance of the lack of a comma after "notice," which makes ambiguous the number and nature of the members of this series, we note that the comma after "by" causes real problems. From it we know that we must now hold onto the package containing these three nouns during an interruption of the prepositional phrase "by. . . ."

"legal process served upon or setoff exercised by a payor bank. .."

It becomes extremely difficult to spot that another series of three is in the making here, since (1) "received by" and "served upon" are not entirely parallel concepts, (2) the lack of a comma after "served upon" creates an ambiguity in the "or" (which could just as easily have been compounding with another participle to modify "process"), and (3) the "by" after "exercised" does not recall with enough confidence the earlier "by" after "received." In sum, it is no sure thing that a "payor bank" ties up everything that has gone before. If the main verb had followed immediately, then at least this question would have been settled. Unfortunately, the commas after "payor bank" inform us that we are to hold onto our triple subject (one part of which is itself tripled) while some qualification intervenes between us and the verb.

"whether or not effective under other rules of law to terminate, suspend or modify the bank's right or duty to pay an item or to charge its customer's account for the item,. . ."

Somewhere in this stretch we drop all the packages. Our tripled subject is held in abeyance while we consider this qualifi- 
cation, which itself is subdivided beyond most reader's abilities to comprehend. In this stretch the sentence is bifurcated to begin with ("whether or not"), then made to refer to rules of law that are "other" than the one we are contemplating, then subdivided in three ("to terminate, suspend or modify") which are themselves bifurcated ("bank's right or duty"), then again bifurcated ("to pay. . .or to charge. . ."). With all of this juggling and scorekeeping, we still have no main verb to tell us what this extraordinarily complex subject does.

"comes too late to so terminate, suspend or modify such right or duty if. . ."

At this point "comes" fails even to look like the main verb. The word "so" tells us to stop reading until we see a word that we have not seen before: "terminate-suspend-or-modifysuch-right-or-duty" might as well have been one word. Our problems are so many and so miserable that only the most grammatically fastidious among us would think to carp about the splitting of an infinitive. (Ironically, this split infinitive, the sole detail that at one time would have been considered an outright "error," troubles the reader's comprehension not at all.) If the reader has survived this far without faltering, the "if" after "duty" should shake what little confidence remains for making it through in one motion.

"the knowledge, notice, stop-order or legal process is received or served and a reasonable time for the bank to act thereon expires or. .."

The multiple units to this point have been burdensome; here they become mystifying. The three-part division of the first of the three-part subject with which the sentence began ("knowledge, notice or stop-order") has now been added to the second of that three-part subject ("legal process") to make a four ("knowledge, notice, stop-order or legal process"). We have not seen a four before; worse, this four is made up of a three plus one, which really makes two (the first two of a three-part subject). (If this is starting to sound confusing at this largo pace, imagine what the mind goes through in trying to read the sentence moderato or vivace.) Worse upon worse, this new four is given two verbs ("is received or served"). The first verb used to go with nouns one, two, and three; the second used to go with noun four. Compacted as they are here, the second verb could logically go with nouns two, three, and four, but 
not one ("knowledge" cannot be "served" in this sense). Though it might go logically, it might not go legally, since there is a possible difference between being served with and "receiving" notice.

At the end of this segment we come to its cruelest word, "or." That word announces that, while we are juggling these new and mystifying numbers, we should be prepared to put all of that into a package to be balanced against whatever is about to appear. For a reader still to be aware of the structure of the whole at this point, the reader has to have committed much of the prose to a temporary memory buffer.

"the setoff is exercised after the bank has done any of the following:"

We now are informed that the three-part subject with which we began (the first part of which, you remember, was itself divided in three) was not a three-part subject at all but rather a two-part subject, the first part of which was divided in two, the first of which was further divided in three:

knowledge

notice

received by bank

stop-order

legal process

-.---- served upon bank

setoff

exercised by bank

The distinction between the two here is that between passivity and activity: in part one, everything happens to the bank; in part two, the bank is doing something. Who possibly could have perceived this was the case at the beginning of the sentence? The great difficulties in the asymmetry of the seemingly symmetrical structure make it necessary to read this section several times before it becomes clear. Return to it six months later and it may again take several readings to rediscover its muddled rhetoric.

Understanding the structure of the material, we can now restructure the whole section effectively. Put like things together. Keep contrasting things contrasted. Put the most important new things into the stress positions. Put whoever's story it is into the topic positions. Keep subjects and verbs together whenever possible. Keep verbs and complements together whenever possible. Do not repeat a long string of words if there is some other way of referring to it accurately. Replace "and" and "or" with slashes when 
they appear to cause ambiguities within clauses; reserve the use of "and" and "or" for connecting larger units in the syntax. Do not allow exceptions to a general rule to interrupt the statement of that general rule. In sum, give the reader as many clues as possible to the shape of the discourse's structure while not distracting the reader from the progress of the discourse's substance. Here is one possible revision of $\S 4-303$.

$\S$ 4-303 When Items Subject to Notice, Stop-Order, Legal Process, or Set-off; Order in Which Items May Be Charged or Certified (revision)

This section concerns the following actions involving a payor bank:

A: The bank (i) receives any knowledge, notice, or stop-order or (ii) has a legal process served upon it;

B: The bank exercises a setoff.

(1) All the above actions come too late to alter the bank's right/duty either to pay an item or to charge its customer's account for the item if

(a) with respect to the actions in (A), the bank has failed to act within a reasonable time; or

(b) with respect to (B), the bank has exercised the setoff after having done any of the following:

(i) accepted or certified the item;

(ii) paid the item in cash;

(iii) settled for the item both without reserving a right to revoke the settlement and without already having such right under statute, clearing house rule or agreement;

(iv) completed the process of posting the item to the indicated account of the drawer, maker or other person to be charged with it;

(v) evidenced either by examining the indicated account or by other action that it has decided to pay the item; or

(vi) become accountable for the amount of the item under Section 4-302 and Subsection (1)(d) of Section 4-213 dealing with the payor 
bank's responsibility for late return of items.

(2) Subsection (1) is operative whether or not the actions involved are effective under other rules of law concerning the bank's right/duty to pay the item or to charge the customer's account for the item.

(3) Subject to the provisions of Subsection (1) items may be accepted, paid, certified, or charged to the indicated account of its customer in any order convenient to the bank.

\section{The Subtlety of Rhetorical Figures}

Although most of the rhetorical problems that plague the UCC can be resolved by the kinds of revision processes I have suggested above, some require an eye trained in classical rhetoric. Occasionally the drafters of the Code have come to terms with a complex thought by engaging in a complex figure of speech without understanding its formal complexity. A subtle change here or there can repair the formal structure and allow it to perform the task for which it was intended. § 9-102(3) exemplifies the problem; its revision seems to me not only to clarify the thought and simplify the reading process, but to introduce a sense of delight into the task and infuse a touch of elegance into the product.

\section{§ 9-102 Policy and Subject Matter of Article (original)}

(3) The application of this Article to a security interest in a secured obligation is not affected by the fact that the obligation is itself secured by a transaction or interest to which this Article does not apply.

This sentence tends to defeat most readers two or three times before its meaning comes clear. One has a sense that a great many pieces of a jigsaw puzzle are on the table, but that the pattern they are meant to fit will not be revealed without a struggle. The problem, I believe, lies not in the multiplicity of terms but in the flawed pattern. That pattern is the rhetorical trope known as chiasmus.

Chiasmus is the repeating of two or more elements of a unit of discourse in reversed order: $\mathrm{x}$ y y $\mathrm{x}$. An example is the memorable line from President Kennedy's inaugural address: "Ask not what your country can do for you; ask what you can do for your country." Most chiasmi are limited to two elements, but three-element chiasmi ( $\mathrm{x}$ y z z y x) are not uncommon. § 9-102(3) contains a highly uncommon and complicated five-element chiasmus: 
1

3

The application of this Article to a security interest in a se4 5 5 cured obligation is not affected by the fact that the obligation is 4 3 2 itself secured by a transaction or interest to which this Article does 1 not apply.

The chiasmus would work well here did it not contain two flaws:

(1) It has not been made clear which pairs of words have one referent and which have two. This turns out to be crucial to the signification of the sentence.

(2) One of the chiastic elements- "secured" (\# 4)-is preceded by a lexical relation ("security" in the first line) that does not take part in the chiasmus. This damages the symmetry and thereby creates confusion for the reader.

The first flaw is the crux of the matter. Elements 1,2 , and 5 are all identical pairs in terms of reference. "Application" and "apply" refer to the same process; the "Article" in both cases is Article 9; and "obligation" refers in both cases to the same legal action. Elements 3 and 4 are the ones that cause the problem. The first "interest" (3) refers to an entirely separate transaction from that referred to by the second "interest." Indeed, it is the very point of the sentence to make this distinction. "Secured" (4) refers to the same action both times, but to different transactions; it acts as a kind of bridge between 3 on one hand and 1,2, and 5 on the other.

As I understand $\S 9-102(3)$, especially in light of Comment $4,^{19}$ it says that even though Article 9 does not cover a real estate mort-

19 § 9-101, Comment 4 reads:

An illustration of subsection(3) is as follows:

The owner of Blackacre borrows $\$ 10,000$ from his neighbor, and secures his note by a mortgage on Blackacre. This Article is not applicable to the creation of the real estate mortgage. Nor is it applicable to a sale of the note by the mortgagee, even though the mortgage continues to secure the note. However, when the mortgagee pledges the note to secure his own obligation to $\mathrm{X}$, this Article applies to the security interest thus created, which is a security interest in an instrument even though the instrument is secured by a real estate mortgage. This Article leaves to other law the question of the effect on rights under the mortgage of delivery or non-delivery of the mortgage or of recording or nonrecording of an assignment of the mortgagee's interest. See Section 9-104(j). But under Section 3-304(5) recording of the assignment does not of itself prevent $\mathrm{X}$ from holding the note in due course. 
gage for the transaction that involves the mortgagee, it may cover future transactions by the mortgagor in which that mortgage happens to play a part. In other words, although it does not cover mortgaging, it may in some cases cover mortgages. To put it another way:

Even though an INTEREST is SECURED outside of ARTICLE 9, ARTICLE 9 may treat it as one of its SECURED INTERESTS.

The concept covered by $\S 9-102(3)$ is in its very essence chiastic. The drafters were correct to use chiasmus to express it, but they constructed the chiasmus incorrectly. It can be repaired by (1) making sure that the chiastic words appear only when they are functioning as chiastic elements, and (2) making sure that the similarity or dissimilarity of chiastic referents is made clear. Three small changes will do the job neatly:

(1) Delete "security" in the first line to avoid creating confusion with the two chiastic appearances of "secured;"20

(2) Notify the reader beforehand that the second "secured" refers to a different transaction by changing its "is" to "was;" and

(3) Reinforce that distinction by changing "a transaction" to "another transaction."

The resulting sentence:

§ 9-102(3) Policy and Subject Matter of Article (revised)

The application of this article to an interest in a secured obligation is not affected by the fact that the obligation was itself secured by another transaction or interest to which this article does not apply.

This repaired chiasmus now articulates the concept more clearly than either the original or any of my several attempts above.

20 There is some question as to whether this deletion would change the substantive meaning of the sentence. Professor Vern Countryman, for twenty years a commercial transactions specialist at the Harvard Law School, offered me the following opinion in a letter of February 10, 1986: "I don't believe your omission of the word 'security' ahead of 'interest' in § 9-102(3) makes a change of substance since the only time Article 9 applies to an interest other than a security interest is in $\$ 9-310$, where it applies to statutory or common law liens on goods, and any security interest in such a lien would be subject to Article 9." Letter on file at The University of Chicago Law Review Office. 


\section{Conclusion}

I hope I have succeeded in demonstrating that the UCC need not be nearly as difficult to read as it currently is. We now have the revision techniques to transform it into "user friendly" prose. Let me repeat something I said at the start: Statutes begin as publicly negotiated settlements of a particular legal problem; but immediately upon enactment they become instruction manuals for those who must use them. Instruction manuals must be clear, to the point, and, above all, helpful.

It may be premature at this point to be overly concerned with the procedure that might be followed should such a wholesale revision be undertaken. In general, however, I suggest that for this initial experiment the rhetorical revisions be drafted by a rhetorician (preferably a legally trained rhetorician), not by the members of the various UCC committees. The revisions for each article then could be submitted to the proper committees, whose main task would be to judge whether the revision had changed in any way the substance of the original. Those judgments should be made only by those members of the committees who have agreed beforehand to the necessity of revision.

The committees would also be faced with certain quasi-substantive decisions, since a certain number of questions would be unearthed by the rhetorical revisions. For example, the work done above on $\S 3-202^{21}$ brought to light several questions about the intentions of the drafters and the consistency of the Code:

(1) Does $\S 3-202$ concern the definition of "negotiation" exclusively, as the title suggests? Or does it define "indorsement" as well, it being a necessary part of the definition of "negotiation"?

(2) If the latter, what exactly is the relationship between the two as far as the purposes of this section are concerned? How should that relationship be reflected in the title of the section?

(3) What other sections of the Code contain definitions of "negotiation" and "indorsement"? Are there inconsistencies? If so, what should be done about them?

These are all significant considerations if we are to have a Code that is truly uniform, consistent, and effective. The rhetorician will

${ }^{21}$ See Section III.C. above. 
be able to raise the questions; the committees will be able to devise answers for them. The revision will not serve to create new problems, but rather to bring to light questions and problems that already exist in the UCC.

My suspicion is that this revision effort would not be as gargantuan a task as it might appear at first glance. Many sections of the Code are already written in prose that fulfills reader expectations most of the time. But however great the effort, it seems to me worth doing if the result would be to bring to fruition the "underlying purposes and policies of this Act"-namely, "to simplify, clarify, and modernize the law governing commercial transactions.",22

Looking yet further ahead, this special procedure I suggest-using a rhetorician for the initial redrafting-need not be repeated for every other statute yet to be written or rewritten. If the revised UCC were as well accepted by the legal community as I predict, it would become a model for the statutory prose of the future. With the new UCC as a finished example at hand, together with a document that clearly sets forth the revision principles, lawyers and legislators could readily learn to revise old prose and produce new prose that would attain a similar clarity of intention, lack of ambiguity, and ease of readability, without the necessity of hiring a rhetorician to make it all possible. In short, this proposed project could change the nature and quality of statutory prose pervasively and permanently. 